\title{
Uncoupling protein 3 and physical activity: the role of uncoupling protein 3 in energy metabolism revisited
}

\author{
Patrick Schrauwen* and Matthijs Hesselink \\ Nutrition and Toxicology Research Institute Maastricht (NUTRIM), Departments of Human Biology and \\ Movement Sciences, Maastricht University, PO Box 616, 6200 MD Maastricht, The Netherlands
}

\begin{abstract}
Physical activity influences energy metabolism in human subjects by increasing activity-induced energy expenditure and resting metabolic rate for several hours after exercise. On the other hand, physical activity increases mechanical energy efficiency, suggesting that trained subjects would need less energy for daily activities. The underlying mechanism by which physical activity influences energy metabolism is largely unknown. The skeletal muscle-specific homologue of uncoupling protein (UCP) 1, UCP3, could possibly play a major role in energy expenditure. UCP3 is, like UCP1, able to uncouple respiration from ATP production. A strong link or association between the UCP3 gene and energy metabolism was found. Furthermore, UCP3 mRNA expression is related to sleeping metabolic rate, and thyroid hormone, a powerful stimulator of energy expenditure, up regulates UCP3. Finally, mice overexpressing UCP3 are hyperphagic but lean. These findings indicated that UCP3 is related to energy metabolism and that UCP3 could have a role in the effect of physical activity on energy expenditure. Thus, acute exercise up regulates UCP3, whereas endurance training results in the down-regulation of UCP3 protein content. Only a minimal amount of physical activity is needed for down-regulation of UCP3. Moreover, there is very strong evidence that UCP3 is negatively related to mechanical energy efficiency, suggesting that the down-regulation of UCP3 with training increases mechanical energy efficiency. Taken together, although the exact function of UCP3 is still unknown, exercise and training studies clearly show that under certain circumstances UCP3 is strongly related to human energy metabolism, possibly as a secondary effect of its (yet) unknown primary function.
\end{abstract}

Uncoupling protein 3: Endurance training: Energy expenditure

Regular physical activity is often prescribed in the prevention and treatment of obesity (Schrauwen \& Westerterp, 2000). The development of obesity is characterized by an imbalance between energy intake and energy expenditure, and physical activity increases the latter. Daily energy expenditure can be divided into three main components: resting metabolic rate (RMR), diet-induced thermogenesis, energy expenditure for activity. Of these three components, energy expenditure for activity varies most and is by definition directly influenced by physical activity. However, in most human subjects the contribution of activity-induced energy expenditure to total daily energy expenditure accounts for only approximately 20-40\% (Westerterp, 1998). On the other hand, RMR is the largest component of daily energy expenditure, accounting for $50-70 \%$ of all energy expended during $24 \mathrm{~h}$ (Ravussin et al. 1986). Thus, it is clear that this component has a major effect on energy balance. In elegant studies done in Pima Indians, it has indeed been shown that inter-individual variations in RMR can influence the development of obesity. In 126 Pima Indians energy expenditure before and after a 4-year follow-up period was measured in a respiration chamber. At the end of the 4-year follow-up period, metabolic rate of subjects who had gained $>10 \mathrm{~kg}$ body weight was compared with that of subjects who did not gain body weight. After adjusting for fat-free mass, fat mass, age and sex, RMR was significantly lower in the weight-gainers $(+15.7 \mathrm{~kg} / 4$ years $)$ as compared with the subjects not gaining weight $(+0 \cdot 1 \mathrm{~kg} / 4$ years; Ravussin et al. 1988). However, the baseline difference in RMR was only $290 \mathrm{~kJ}(70 \mathrm{kcal}) / \mathrm{d}$, indicating the enormous impact of small differences in RMR on the susceptibility to obesity. The reason for the inter-individual variation in resting energy needs is not yet clear, but studies of twins have indicated

\footnotetext{
Abbreviations: FFA, non-esterified fatty acids; RMR, resting metabolic rate; UCP, uncoupling protein; $V_{\mathrm{O}_{2}}, \mathrm{O}_{2}$ consumption *Corresponding author: Dr P. Schrauwen, fax +31 43 3670976, email p.schrauwen@ @b.unimaas.nl
} 
that up to $40 \%$ of the unexplained variance in RMR might be explained by genetic factors (Fontaine et al. 1985).

\section{Physical activity and energy metabolism}

Since energy expenditure has an important impact on the overall energy balance, many researchers have studied the effect of physical activity on the energy expenditure component of energy balance. Physical activity will increase activity-induced energy expenditure. Westerterp (1998) re-evaluated the available literature on the effect of exercise interventions on total daily energy expenditure, as measured with doubly-labelled water. He concluded that although exercise did not increase spontaneous physical activity, the exercise interventions resulted in an increase in $24 \mathrm{~h}$ energy expenditure. Remarkably, however, the increase in total energy expenditure was calculated to be twice the workload of the training regimen, indicating that the increase in energy expenditure was not fully accounted for by an increase in activity-induced exercise (Westerterp, 1998).

Apart from an effect of physical activity on total energy expenditure, many researchers have examined whether regular physical activity (or training) can influence RMR. Since the major determinant of RMR is the amount of fat-free mass, any training-induced increase in the latter will therefore also increase RMR. However, whether regular physical activity also increases RMR independent of changes in fat-free mass is less clear. Some studies have found a positive effect of physical activity on RMR (Tremblay et al. 1986; Poehlman et al. 1988, 1994; Pratley et al. 1994; Wilmore et al. 1998), whereas other studies have found no effect (Davis et al. 1983; Meijer et al. 1991; Schulz et al. 1991; Broeder et al. 1992; Westerterp et al. 1994). Part of this controversy can be explained by the residual effect of the exercise bout preceding the measurement of RMR. There is compelling evidence that acute exercise leads to an increase in energy expenditure after exercise (also referred to as excess post-exercise $\mathrm{O}_{2}$ consumption $\left(V_{\mathrm{O}_{2}}\right)$ ), and this effect can last for several hours and might still affect RMR or sleeping metabolic rate on the following day. For example, the effect of cycling exercise on energy metabolism was studied using a respiration chamber, and sleeping metabolic rate measured during the second night (after exercise) was found to be approximately $7 \%$ higher than during the first night (before exercise; WH Saris and P Schrauwen, unpublished results). This finding is in agreement with results obtained by other researchers, who showed an elevated RMR (or sleeping metabolic rate) after exercise (Bielinski et al. 1985; Bahr et al. 1987). Thus, the positive effect of training on RMR reported in some studies might be explained by the residual effect of the last exercise bout on RMR. In this context Tremblay et al. (1988) found that RMR is reduced by $6.6 \%$ compared with the baseline measurement (acutely after the last exercise bout) when highly-trained subjects suspend their training programme for $3 \mathrm{~d}$, indicating that endurance training has no long-lasting effect on RMR. Similar findings have been found in endurance-trained females when measurements are done $87 \mathrm{~h}$ post-exercise (Herring et al. 1992). Thus, apart from the short-term exercise-induced increase in RMR, there is little evidence for a long-lasting effect of endurance training on RMR. This finding indicates that physical activity has to be performed on a regular basis in order to maintain its positive effect on energy balance.

Moreover, it has even been suggested that, in order to be able to maintain energy balance, the human body increases its energy efficiency in response to frequent endurance training. Such an increase in energy efficiency would be a beneficial adaptation in relation to exercise performance, but would diminish the positive effect of regular training on the prevention and treatment of obesity. Furthermore, the improved energy efficiency would make the body more susceptible to reaching a positive energy balance when the training programme is discontinued, further indicating that physical activity will only positively affect energy balance as long as it is performed on a regular and continued basis. The energy efficiency of the human body becomes apparent during exercise, when 10-30\% of the energy expended can be used for external work (defined as mechanical energy efficiency), whereas the remaining ATP production is used for homeostasis or dissipated as heat. Endurance training has indeed been shown to improve mechanical energy efficiency (Gaesser \& Brooks, 1975; Gissane et al. 1991), indicating that training indeed decreases energy needs for the same level of physical activity. Furthermore, there are some reports showing that mechanical energy efficiency is related to body-weight regulation (Freyschuss \& Melcher, 1978; Lammert \& Hansen, 1982) and the rapid body-weight gain observed in some elite athletes after their professional career also suggests that efficiency might be enhanced. However, scientific data relating to the latter effect is lacking and more work in this field is necessary.

\section{Uncoupling protein 3: a human homologue of uncoupling protein 1 ?}

The mechanisms by which training could influence energy expenditure and mechanical energy efficiency are largely unknown. In human subjects skeletal muscle seems to play a major role in determining energy expenditure. For example, it has been shown that $40-50 \%$ of the adrenalin-induced thermogenesis in human subjects can be attributed to skeletal muscle (Astrup et al. 1985; Simonsen et al. 1993). In 1997 a muscle-specific uncoupling protein (UCP), UCP3, was discovered that might well be involved in the regulation of energy expenditure.

In living cells ATP is continuously resynthesised from ADP, by the metabolism of substrates such as fat, carbohydrate and proteins, resulting in the production of NADH and $\mathrm{FADH}_{2}$. Subsequently, NADH and $\mathrm{FADH}_{2}$ can be oxidized to $\mathrm{NAD}^{+}$, FAD and $\mathrm{H}^{+}$in the respiratory chain. According to the Nobel prize-winning chemi-osmotic hypothesis of Mitchell (1966), the protons are transported to the cytosolic side of the inner mitochondrial membrane by a series of reactions. Thus, a proton gradient across the inner mitochondrial membrane is generated, which causes the protons to flow back across the inner mitochondrial membrane through the so-called $\mathrm{F}_{0}-\mathrm{F}_{1}$ complex. In tightlycoupled mitochondria the energy thus generated is used by ATPase to transform ADP into ATP. However, build up of the proton gradient can be diminished by the action of UCP. These proteins transport either protons or fatty acid anions across the inner mitochondrial membrane, thereby lowering 
the proton gradient and thus uncoupling mitochondrial respiration from ATP production. This process will result in lower energy efficiency and possibly increased energy expenditure.

In rodents such a UCP (UCP1) is responsible for the wellknown thermogenic activity of brown adipose tissue (Nicholls \& Locke, 1984). In 1997 two human homologues of UCP1, UCP2 (Fleury et al. 1997; Gimeno et al. 1997), which is present in a wide variety of tissues, and UCP3 (Boss et al. 1997; Vidal-Puig et al. 1997), expression of which is restricted to skeletal muscle, were discovered. Since UCP3 expression is restricted to skeletal muscle this particular protein was considered to be of importance in skeletal muscle energy metabolism. Similar to UCP1, UCP3 has been shown to lower the proton gradient across the inner mitochondrial membrane (Gong et al. 1997). Furthermore, mitochondria isolated from mice lacking UCP3 show a decreased state 4 respiration (rate of $\mathrm{O}_{2}$ consumption after all ADP in the mitochondria has been phosphorylated to form ATP), indicating improved coupling (Vidal-Puig et al. 2000), whereas mitochondria isolated from mice overexpressing UCP3 show an increased state 4 respiration (Clapham et al. 2000). Also, in vivo, there are indications that UCP3 indeed is able to uncouple respiration from ATP production. The rate of ATP synthesis:tricarboxylic acid cycle flux, measured using ${ }^{31} \mathrm{P}$ NMR, was found to be increased in mice lacking UCP3, indicating a 2-4-fold higher coupling of oxidative phosphorylation (Cline et al. 2001).

\section{Uncoupling protein 3 is related to energy expenditure in human subjects}

The finding that UCP3 can uncouple respiration from ATP production suggests that it might be involved in the regulation of human energy metabolism. First evidence for a relationship between UCP3 and energy metabolism came from genetic studies. Bouchard et al. (1997) found that markers in the vicinity of the UCP2 and UCP3 genes (which are only $7 \mathrm{~kb}$ apart) were very strongly linked $(P=0.000002)$ to RMR. Direct screening of the UCP2 and UCP3 genes revealed several polymorphisms, which were used to examine the association between UCP2 and UCP3 and energy metabolism. It was found that in Pima Indians an alanine $\rightarrow$ valine substitution in exon 4 and a 45 bp insertion/ deletion in exon 8 of the UCP 2 gene were associated with sleeping metabolic rate and $24 \mathrm{~h}$ energy expenditure, as measured in a respiration chamber (Walder et al. 1998). This polymorphism has also been associated with $24 \mathrm{~h}$ energy expenditure in a Danish population (Astrup et al. 1999), as well as with exercise efficiency (Buemann et al. 2001). Due to the close genetic mapping of UCP2 and UCP3, the association between energy expenditure and UCP2 might also reflect an association between UCP3 and energy metabolism.

A polymorphism in exon 3 of the $U C P 3$ gene was found to be related to RMR, both before and after a period of overfeeding, but not with overfeeding-induced changes in RMR (Ukkola et al. 2001). Recently, Kimm et al. (2002) found that a $\mathrm{C} \rightarrow \mathrm{T}$ substitution in exon 5 was associated with RMR in African-American women, but not in white women, suggesting that this variant might explain (part of) the racial differences in resting energy expenditure. However, negative associations between polymorphisms in the UCP 2 and UCP3 genes and energy metabolism have also been found (Klannemark et al. 1998; Lentes et al. 1999; Yanovski et al. 2000). Thus, together these studies indicate, but do not conclusively prove, that there is evidence for a role of UCP2 and UCP3 in energy metabolism. A more direct assessment of a role for UCP3 in energy metabolism comes from studies in which UCP3 mRNA expression and/or protein content is measured and directly related to energy expenditure. For example, in Pima Indians it was found that the mRNA expression of UCP3 was positively correlated with sleeping metabolic rate (which accounts for approximately $60 \%$ of total energy expenditure in human subjects; Schrauwen et al. $1999 b$ ). Furthermore, weight reduction, which reduces $\mathrm{RMR}$, also leads to a reduction in UCP3 mRNA expression and protein content (Schrauwen et al. 2000; Vidal-Puig et al. 1999). During cold exposure, extra heat is produced to maintain body temperature. In accordance with a role for UCP3 in energy metabolism, acute cold exposure in mice resulted in a 3-fold increase in UCP3 protein content, accompanied by a pronounced lowering of mitochondrial membrane potential and dissipation of energy as heat (Simonyan et al. 2001). It was shown recently that in human subjects exposed to mild cold for $60 \mathrm{~h} \mathrm{UCP} 3$ protein content is not (yet) changed, but is related to sleeping metabolic rate and $24 \mathrm{~h}$ energy expenditure. However, UCP3 mRNA expression is down regulated, suggesting that prolonged cold exposure also decreases UCP3 protein content. Thus, this result indicates that, although basal UCP3 protein content is related to energy metabolism, the function of UCP3 is not in the adaptation to cold (Schrauwen et al. 2002c). Recently, de Lange et al. (2001) reported evidence of a role for UCP3 in thyroid hormone-induced thermogenesis. In hypothyroid rats skeletal muscle UCP3 protein content and RMR, measured for $144 \mathrm{~h}$ after thyroid hormone injection, both peaked $65 \mathrm{~h}$ after thyroid hormone injection. Moreover, mitochondria showed increased uncoupling activity when UCP3 protein content was high (de Lange et al. 2001). In human subjects Lebon et al. (2001) showed that thyroid hormone treatment increased tricarboxylic acid cycle flux in combination with unchanged ATP synthesis, indicative of increased mitochondrial uncoupling. Although UCP3 was not measured, it is tempting to suggest that increased UCP3 content was responsible for the increased mitochondrial uncoupling. Finally, in mice overexpressing UCP3, an increased metabolic rate has been found (Clapham et al. 2000). Together, these studies indicate that high levels of UCP3 can lead to elevated energy expenditure.

However, there is also evidence that the primary physiological function of UCP3 is not the regulation of energy expenditure! Mice lacking UCP3 have normal energy expenditure, even though their mitochondria are more tightly coupled (Gong et al. 2000; Vidal-Puig et al. 2000). Furthermore, fasting up regulates UCP3, while in this condition energy conservation is observed (Millet et al. 1997). As mentioned earlier, the finding that prolonged cold exposure decreases UCP3 expression but increases energy metabolism is also in contrast with a major role for UCP3 in the regulation of energy metabolism (Schrauwen et al. $2002 c$ ). Thus, based on the available literature, there is clear 
evidence that UCP3 is indeed related to energy metabolism, and that high levels of UCP3 could even contribute to increased energy expenditure by uncoupling mitochondria. However, the uncoupling function of UCP3 is most likely not primarily the regulation of energy expenditure, but has another, yet to be determined, physiological function. It has, for example, been shown that a high proton gradient across the mitochondrial membrane results in the production of reactive oxygen species (Skulachev, 1998), and by lowering this proton gradient UCP3 could prevent the production of reactive oxygen species. Alternatively, the observation that UCP3 is up regulated in the fasted state (Boss et al. 1998b) and that plasma non-esterified fatty acids (FFA) levels are able to up regulate UCP3 mRNA (Khalfallah et al. 2000) has led to the suggestion that UCP3 might be involved in fatty acid metabolism (for a more extensive review of the putative functions of UCP3, see Dulloo \& Samec, 2001; Hagen \& Vidal-Puig, 2002; Schrauwen \& Hesselink, 2002).

\section{Uncoupling protein 3, energy metabolism and physical activity}

Based on the previously mentioned evidence that UCP3 is at least related to energy metabolism, it is a likely candidate for explaining the effect of acute exercise and long-term endurance training on energy expenditure and efficiency. The first evidence of a role for UCP3 in training adaptation again came from genetic studies. Lanouette et al. (2001) showed that a polymorphism in the UCP3 gene (a microsatellite located in intron 6) was associated with the changes in BMI and percentage body fat induced by a 20 -week endurance training programme. Although it is not known whether this polymorphism in intron 6 , which obviously does not alter the amino acid sequence of UCP3, does influence UCP3 mRNA, protein content or uncoupling activity, this study suggests that UCP3 might indeed be involved in training-induced adaptations in energy metabolism. Furthermore, an alanine $\rightarrow$ valine substitution in exon 4 of the UCP2 gene was associated with $24 \mathrm{~h}$ energy expenditure; subjects with the val/val genotype had lower $24 \mathrm{~h}$ energy expenditure compared with subjects with the ala/val and ala/ala genotype. However, surprisingly, $24 \mathrm{~h}$ spontaneous physical activity was approximately $20 \%$ higher in subjects with the val/val genotype, thereby compensating for the lower resting $24 \mathrm{~h}$ energy expenditure in this genotype (Astrup et al. 1999). Interestingly, in another report the same group showed that subjects with the $\mathrm{val} / \mathrm{val}$ genotype were characterized by a higher mechanical energy efficiency, determined at three different workloads (Buemann et al. 2001). It is tempting to speculate that the polymorphism in the $U C P 2$ gene, close to the $U C P 3$ gene, is associated with lower UCP2 and/or UCP3 content, thereby explaining the lower resting energy expenditure and the increased mechanical energy efficiency. Alternatively, it is possible that the increased spontaneous physical activity (for any unknown reason) is the primary effect and that the lower resting energy expenditure and improved mechanical energy efficiency are compensatory adaptations to the increased activity.

At the mRNA level, the effect of physical activity on UCP3 was studied by Hjeltnes et al. (1999). They found a 4.1-fold higher level of UCP3 mRNA in skeletal muscle of subjects with a complete chronic lesion of the cervical spinal cord compared with healthy subjects, indicating that muscle inactivity leads to a pronounced up-regulation of UCP3. Interestingly, when these tetraplegic subjects were exercise trained for 8 weeks, using electrically-stimulated leg cycling, UCP3 mRNA expression was down regulated by approximately $50 \%$. Also in rats, denervation (and thus inactivation) resulted in a $331 \%$ increase in UCP3 mRNA expression in gastrocnemius muscle, although opposite effects were found in mouse (Cortright et al. 1999).

Several studies have examined whether UCP3 is involved in the (endurance) training-induced adaptation of energy expenditure. Boss et al. (1998a) showed that the mRNA expression of UCP3 was significantly lower $(P<0.05)$ after 8 weeks of endurance training in rats, when measured 24-30 $\mathrm{h}$ after the last exercise bout. To examine whether a similar effect is found in human subjects, UCP3 mRNA expression was compared in endurance-trained athletes and untrained subjects (Schrauwen et al. 1999a). It was found that UCP3 mRNA expression was significantly lower in endurance-trained athletes $(P=0.028)$ and that the level of UCP3 mRNA expression was very strongly and negatively correlated with aerobic capacity (maximal $V_{\mathrm{O}_{2}} ; r-0.61$, $P=0.009$ ). This correlation remained significant when only untrained subjects were considered $(r-0.86, P=0.028)$, illustrating that the level of physical fitness is related to UCP3 mRNA expression. Furthermore, mechanical energy efficiency was determined in all subjects and it was found that UCP3 mRNA expression was negatively correlated $(r-0.56, P=0.019)$ with this energy efficiency, suggesting that the reduction in $\mathrm{UCP} 3$ with training might be responsible for the improvement in efficiency. Similar findings were reported recently by Russell et al. (2002). They found that the lower level of UCP3 mRNA expression in their endurance-trained athletes was positively correlated with the slow component of $V_{\mathrm{O}_{2}}$ kinetics. Thus, in healthy individuals exercising at an intensity above the lactate threshold, $V_{\mathrm{O}_{2}}$ gradually increases without an increase in workload. This increase in $V_{\mathrm{O}_{2}}$ is termed the slow component of $V_{\mathrm{O}_{2}}$, and it suggests a possible decrease in mechanical energy efficiency. However, these studies only examined UCP3 mRNA expression and therefore, in collaboration with Russell's group, it was confirmed recently that the lower level of UCP3 mRNA in endurance-trained athletes can be extended to the protein levels (Russell et al. 2003). Thus, UCP3 protein was $46 \%$ lower in endurance-trained individuals compared with untrained subjects. Together, these studies show that endurance training down regulates UCP3 in human subjects, and that this down-regulation of UCP3 coincides with improved mechanical energy efficiency. To confirm the relationship between UCP3 protein content and physical fitness (maximal $V_{\mathrm{O}_{2}}$ ) and mechanical energy efficiency, baseline data from a recent study was re-analysed (Schrauwen et al. 2002a). In this study seven untrained men (age 22.7 (SE 0.6) years, BMI 23.8 (SE 1.0) $\mathrm{kg} / \mathrm{m}^{2}$; maximal $V_{\mathrm{O}_{2}} 3852$ (SE 211) $\mathrm{ml} / \mathrm{min}$ ) exercised at $50 \%$ maximal $V_{\mathrm{O}_{2}}$ for $2 \mathrm{~h}$ and a muscle biopsy was taken before the exercise bout. Energy expenditure during exercise was determined by measuring $V_{\mathrm{O}_{2}}$ and $\mathrm{CO}_{2}$ production and using this energy expenditure to calculate 
mechanical energy efficiency. In a separate test, 1 week before sampling of the muscle biopsy, maximal $V_{\mathrm{O}_{2}}$ was determined (Schrauwen et al. 2002a). It was found that the level of UCP3 (after an overnight fast) was very strongly and negatively correlated with maximal $V_{\mathrm{O}_{2}}$ adjusted for body weight $(r-0.94, P=0.0018$; Fig. 1(a)), as well as with mechanical energy efficiency $(r-0.97, \quad P=0.0002$; Fig. 1(b)). These findings indicate that even in a group of untrained subjects UCP3 protein content is very strongly related to the level of physical fitness and to the subject's energy efficiency! Interestingly, it was found recently that a mild activity programme for 3 months (three times
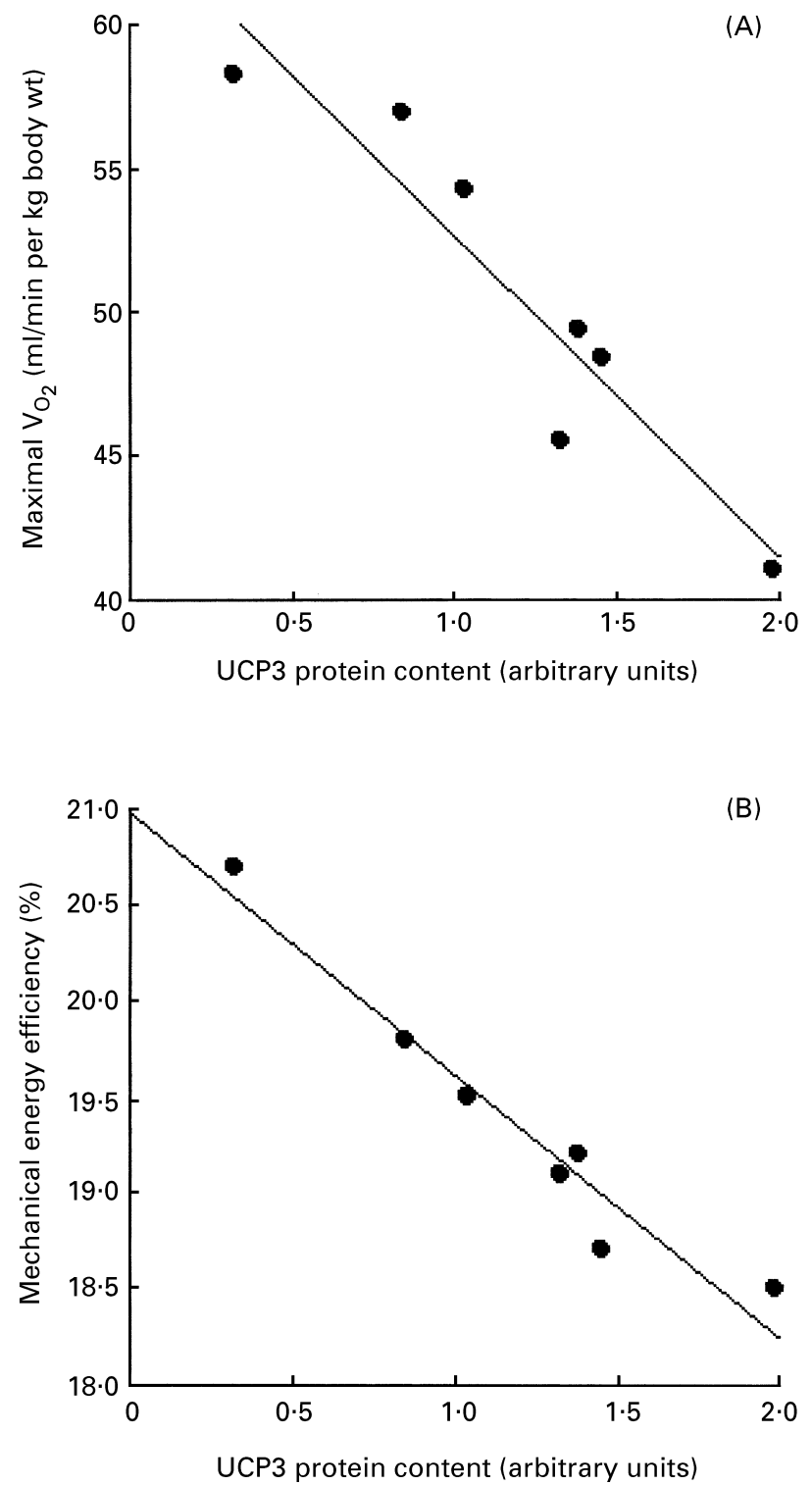

Fig. 1. Relationship between skeletal muscle uncoupling protein (UCP) 3 content and (a) maximal oxygen consumption $\left(V_{\mathrm{O}_{2}}\right)$ relative to body weight $(r-0.94, P=0.0018)$ and (b) energy efficiency during exercise $(r-0.97, P=0.0002)$ in seven untrained men (age 22.7 (SE 0.6) years, BMI 23.8 (SE 1.0) kg/m²; maximal $V_{\mathrm{O}_{2}} 3852$ (SE 211) $\mathrm{ml} / \mathrm{min}$ ) who exercised at $50 \%$ maximal $V_{\mathrm{O}_{2}}$ for $2 \mathrm{~h}$ and from whom a muscle biopsy was taken before the exercise bout. per week cycling exercise at $40 \%$ maximal workload for approximately $2 \mathrm{~h} /$ week) in sedentary middle-aged subjects decreased UCP3 protein content by approximately $30 \%$ (Schrauwen et al. 2001; 2002b), suggesting that 'training'induced reductions in UCP3 can occur rapidly and with a minimal increase in physical activity. In accordance with this possibility, it was found recently that UCP3 protein content tended to be lower $(P=0 \cdot 08)$ and mechanical energy efficiency higher $(P=0 \cdot 08)$ after only 2 weeks of training in untrained young subjects (P Schrauwen and MKC Hesselink, unpublished results). Together these studies clearly show that endurance training and physical activity rapidly down regulate $\mathrm{UCP} 3$, and there are very strong indications that this down-regulation of UCP3 affects energy efficiency. Very recently, direct evidence for the latter has come from mice overexpressing UCP3. During a series of isometric tetani in muscle fibres isolated from these mice, heat production was found to be increased, illustrating that more energy was dissipated as heat and indicating lower energy efficiency (Curtin et al. 2002).

Although these studies all suggest reduced levels of UCP3 after training, there are also contrasting findings. For example, chronic exercise for 9 weeks did not alter UCP3 mRNA expression in the rat (Cortright et al. 1999). An explanation for the lack of effect of training on UCP3 in the latter study could relate to the time interval between the last exercise bout and muscle sampling, which was only a few hours in this study, whereas in the other studies there was at least $24 \mathrm{~h}$ between the last exercise bout and UCP3 determination. It was shown that after 2 weeks of swimming training, UCP3 mRNA expression in skeletal muscle was up regulated approximately $14-18$-fold $3 \mathrm{~h}$ after the last exercise bout, but was not different from pre-training levels when measured $22 \mathrm{~h}$ after the last exercise bout (TsuboyamaKasaoka et al. 1998). Furthermore, 1 week of treadmill running resulted in a 4.7-fold up-regulation of UCP3 mRNA $3 \mathrm{~h}$ after exercise, but reduced levels when measured $44 \mathrm{~h}$ post-exercise (Tsuboyama-Kasaoka et al. 1998). Thus, these results clearly indicate that sufficient time is needed between the last bout of exercise and the determination of UCP3 expression in order to find an effect of endurance training rather than from acute exercise on UCP3 level. Furthermore, the findings suggest that acute exercise and endurance training might have opposite effects on UCP3 mRNA expression.

\section{Effect of acute exercise on uncoupling protein 3}

The suggested up-regulation of UCP3 with acute exercise encouraged researchers to examine whether UCP3 plays a role in the elevated post-exercise energy expenditure (excess post-exercise $V_{\mathrm{O}_{2}}$ ), which can be sustained for several hours. In rodents UCP3 mRNA expression was significantly $(P<0.05)$ up regulated $1-3 \mathrm{~h}$ after an acute exercise bout (Tsuboyama-Kasaoka et al. 1998; Cortright et al. 1999). This up-regulation of UCP3 after acute exercise seems to be highly specific; the very pronounced up-regulation of UCP3 mRNA $200 \mathrm{~min}$ after either running or swimming exercise was not accompanied by changes in other mitochondrial genes (Zhou et al. 2000). Since during exercise plasma FFA levels are increased and AMP-activated protein kinase, 
a key regulator of enzymes involved in energy and substrate metabolism, is activated under situations of elevated FFA levels (Ruderman et al. 1999), it was suggested that activation of AMP-activated protein kinase is necessary for the up-regulation of UCP3 mRNA expression. To test this hypothesis 5-aminoimidazole-4-carboxamide 1- $\beta$-Dribofuranoside, which mimics the effects of AMP on activation of AMP-activated protein kinase, was administered and it was found that this treatment also resulted in up-regulation of UCP3. Similar results were obtained by Pedersen et al. (2001), who showed that electrical stimulation of skeletal muscle in vitro resulted in an up-regulation of UCP3 mRNA, and that this up-regulation could be mimicked by 5 -aminoimidazole-4-carboxamide $1-\beta$-D-ribofuranoside. In human subjects, also, it was found that UCP3 mRNA expression is up regulated 3-6-fold $4 \mathrm{~h}$ after an acute exercise bout (Pilegaard et al. 2000). Again, this effect might have been due to elevated plasma FFA levels during exercise. To examine whether the up-regulation of UCP3 after acute exercise in human subjects is related to the increased energy expenditure, or is simply an effect of elevated plasma FFA levels, the effect of acute exercise $\left(2 \mathrm{~h}\right.$ at $50 \%$ maximal $\left.\mathrm{V}_{\mathrm{O}_{2}}\right)$ on UCP3 mRNA expression 0,1 and $4 \mathrm{~h}$ post-exercise was tested once in the fasted state and once in the glucose-fed state (Schrauwen et al. 2002a). It was observed that energy expenditure during and after exercise was not influenced by glucose administration, whereas glucose drinks inhibited plasma FFA levels and fat oxidation. UCP3 mRNA expression was up regulated $4 \mathrm{~h}$ after exercise, but only in the fasted situation. This result indicated that the up-regulation of UCP3 with acute exercise was more likely to be linked to changes in fatty acid metabolism than to changes in energy expenditure. These findings were confirmed recently by Pilegaard et al. (2002), who examined the effect of glycogen content on up-regulation of UCP3 mRNA after exercise. Subjects performed a $1 \mathrm{~h}$ cycling exercise bout at $70 \%$ maximal workload followed by a $1 \mathrm{~h}$ two-arm cycling exercise bout to lower glycogen levels. Subsequently, subjects consumed either a low-carbohydrate (resulting in low glycogen content) or a high-carbohydrate diet (resulting in high glycogen content). On the following day subjects performed a $3 \mathrm{~h}$ exercise bout to examine the effect of glycogen content on UCP3 mRNA expression. It was found that UCP3 mRNA expression was significantly increased $(P<0.05) 2 \mathrm{~h}$ after exercise, but only in the low glycogen condition. Since plasma FFA levels were also significantly higher $(P<0.05)$ in the low glycogen trial, these results again suggest that changes in plasma FFA levels might be responsible for the up-regulation of UCP3 after acute exercise (Pilegaard et al. 2002). Whether in human subjects, also, activation of AMPK is involved still needs to be examined. Taken together, there is little evidence that the upregulation of UCP3 after acute exercise is triggered by elevated energy expenditure. Rather, the up-regulation of UCP3 after acute exercise seems to be more related to changes in fatty acid metabolism. Recently, it was postulated that the primary function of UCP3 would be in the handling of those fatty acids that cannot be oxidized (Schrauwen et al. 2001). After acute exercise in the fasted state more fatty acids are released from the adipose tissue than can be oxidized, thus explaining the up-regulation of UCP3. However, with endurance training the capacity to oxidize fatty acids would increase, reducing the need for high levels of UCP3. As a secondary effect of the reduced UCP3 content with training, mechanical energy efficiency would be improved. However, more research is needed to test this hypothesis and to examine the physiological function of UCP3 in human skeletal muscle.

\section{Conclusion}

Physical activity can affect energy metabolism in human subjects. Apart from increasing the daily energy requirement for physical activity, it has also been suggested that physical activity might improve energy efficiency. The human skeletal muscle-specific UCP3 might play a role in this activity-induced alteration in energy metabolism. UCP3 is down regulated by endurance training and strongly related to physical fitness. Furthermore, there is strong evidence that UCP3 protein content is a determinant of mechanical energy efficiency. Although at present there is evidence that the primary physiological function of UCP3 is not the regulation of energy expenditure, there is also very strong evidence that UCP3, as a secondary effect of its physiological function, influences energy metabolism. Thus, UCP3 can still be considered as a potential target for the elevation of energy expenditure in the treatment and prevention of obesity and diabetes; however, first it is necessary to learn more about the exact physiological function of UCP3.

\section{Acknowledgement}

The research of P. S. has been made possible by fellowships from the Royal Netherlands Academy of Arts and Sciences (KNAW) and the Netherlands Organization for Scientific Research (NWO).

\section{References}

Astrup A, Bulow J, Madsen J \& Christensen NJ (1985) Contribution of BAT and skeletal muscle to thermogenesis induced by ephedrine in man. American Journal of Physiology 248, E507-E515.

Astrup A, Toubro S, Dalgaard LT, Urhammer SA, Sørensen TIA \& Pedersen O (1999) Impact of the v/v 55 polymorphism of the uncoupling protein 2 gene on 24-h energy expenditure and substrate oxidation. International Journal of Obesity and Related Metabolic Disorders 23, 1030-1034.

Bahr R, Ingnes I, Vaage O, Sejersted OM \& Newsholme EA (1987) Effect of duration of exercise on excess postexercise $\mathrm{O}_{2}$ consumption. Journal of Applied Physiology 62, 485-490.

Bielinski R, Schutz Y \& Jéquier E (1985) Energy metabolism during the postexercise recovery in man. American Journal of Clinical Nutrition 42, 69-82.

Boss O, Samec S, Desplanches D, Mayet M-H, Seydoux J, Muzzin P \& Giacobino J-P (1998a) Effect of endurance training on mRNA expression of uncoupling proteins 1,2 and 3 in the rat. FASEB Journal 12, 335-339.

Boss O, Samec S, Kühne F, Bijlenga P, Assimacopoulos-Jeannet F, Seydoux J, Giacobino J-P \& Muzzin P (1998b) Uncoupling protein-3 expression in rodent skeletal muscle is modulated by 
food intake but not by changes in environmental temperature. Journal of Biological Chemistry 273, 5-8.

Boss O, Samec S, Paoloni-Giacobino A, Rossier C, Dulloo A, Seydoux J, Muzzin P \& Giacobino J-P (1997) Uncoupling protein-3: a new member of the mitochondrial carrier family with tissue-specific expression. FEBS Letters 408, 39-42.

Bouchard C, Pérusse L, Chagnon YC, Warden G \& Ricquier D (1997) Linkage between markers in the vicinity of the uncoupling protein 2 gene and resting metabolic rate in humans. Human Molecular Genetics 6, 1887-1889.

Broeder CE, Burrhus KA, Svanevik LS \& Wilmore JH (1992) The effects of either high-intensity resistance or endurance training on resting metabolic rate. American Journal of Clinical Nutrition 55, 802-810.

Buemann B, Schierning B, Toubro S, Bibby B, Sorensen T, Dalgaard L, Pedersen O \& Astrup A (2001) The association between the val/ala-55 polymorphism of the uncoupling protein 2 gene and exercise efficiency. International Journal of Obesity and Related Metabolic Disorders 25, 467-471.

Clapham JC, Arch JR, Chapman H, Haynes A, Lister C, Moore GB et al. (2000) Mice overexpressing human uncoupling protein-3 in skeletal muscle are hyperphagic and lean. Nature 406, 415-418.

Cline GW, Vidal-Puig AJ, Dufour S, Cadman KS, Lowell BB \& Shulman GI (2001) In vivo effects of uncoupling protein-3 gene disruption on mitochondrial energy metabolism. Journal of Biological Chemistry 276, 20240-20244.

Cortright RN, Zheng D, Jones JP, Fluckey JD, DiCarlo SE, Grujic D, Lowell BB \& Dohm GL (1999) Regulation of skeletal muscle UCP-2 and UCP-3 gene expression by exercise and denervation. American Journal of Physiology 276, E217-E221.

Curtin NA, Clapham JC \& Barclay CJ (2002) Excess recovery heat production by isolated muscles from mice overexpressing uncoupling protein-3. Journal of Physiology 542, 231-235.

Davis JR, Tagliaferro AR, Kertzer R, Gerardo T, Nichols J \& Wheeler J (1983) Variations in dietary-induced thermogenesis and body fatness with aerobic capacity. European Journal of Applied Physiology and Occupational Physiology 50, 319-329.

de Lange P, Lanni A, Beneduce L, Moreno M, Lombardi A, Silvestri E \& Goglia F (2001) Uncoupling protein-3 is a molecular determinant for the regulation of resting metabolic rate by thyroid hormone. Endocrinology 142, 3414-3420.

Dulloo AG \& Samec S (2001) Uncoupling proteins: their roles in adaptive thermogenesis and substrate metabolism reconsidered. British Journal of Nutrition 86, 123-139.

Fleury C, Neverova M, Collins S, Raimbault S, Champigny O, Levi-Meyrueis C, Bouillaud F, Seldin MF, Surwit RS, Ricquier D \& Warden CH (1997) Uncoupling protein-2: a novel gene linked to obesity and hyperinsulinemia. Nature Genetics $\mathbf{1 5}$, 269-273.

Fontaine E, Savard R, Tremblay A, Despres JP, Poehlman E \& Bouchard C (1985) Resting metabolic rate in monozygotic and dizygotic twins. Acta Geneticae Medicae et Gemellologiae 34, 41-47.

Freyschuss U \& Melcher A (1978) Exercise energy expenditure in extreme obesity: influence of ergometry type and weight loss. Scandinavian Journal of Clinical and Laboratory Investigation 38, 753-759.

Gaesser GA \& Brooks GA (1975) Muscular efficiency during steady-state exercise: effects of speed and work rate. Journal of Applied Physiology 38, 1132-1139.

Gimeno RE, Dembski M, Weng X, Deng N, Shyjan AW, Gimeno CJ, Iris F, Ellis SJ, Woolf EA \& Tartaglia LA (1997) Cloning and characterization of an uncoupling protein homolog: a potential molecular mediator of human thermogenesis. Diabetes 46, 900-906.
Gissane C, Corrigan DL \& White JA (1991) Gross efficiency responses to exercise conditioning in adult males of various ages. Journal of Sports Sciences 9, 383-391.

Gong D-W, He Y, Karas M \& Reitman M (1997) Uncoupling protein-3 is a mediator of thermogenesis regulated by thyroid hormone, B3-adrenergic agonists, and leptin. Journal of Biological Chemistry 272, 24129-24132.

Gong DW, Monemdjou S, Gavrilova O, Leon LR, Marcus-Samuels B, Chou CJ, Everett C, Kozak LP, Li C, Deng C, Harper ME \& Reitman ML (2000) Lack of obesity and normal response to fasting and thyroid hormone in mice lacking uncoupling protein-3. Journal of Biological Chemistry 275, 16251-16257.

Hagen T \& Vidal-Puig A (2002) Mitochondrial uncoupling proteins in human physiology and disease. Minerva Medica 93, 41-57.

Herring JL, Mole PA, Meredith CN \& Stern JS (1992) Effect of suspending exercise training on resting metabolic rate in women. Medicine and Science in Sports and Exercise 24, 59-65.

Hjeltnes N, Fernström M, Zierath JR \& Krook A (1999) Regulation of UCP2 and UCP3 by muscle disuse and physical activity in tetraplegic subjects. Diabetologia 42, 826-830.

Khalfallah Y, Fages S, Laville M, Langin D \& Vidal H (2000) Regulation of uncoupling protein-2 and uncoupling protein-3 mRNA expression during lipid infusion in human skeletal muscle and subcutaneous adipose tissue. Diabetes 49, 25-31.

Kimm SY, Glynn NW, Aston CE, Damcott CM, Poehlman ET, Daniels SR \& Ferrell RE (2002) Racial differences in the relation between uncoupling protein genes and resting energy expenditure. American Journal of Clinical Nutrition 75, 714-719.

Klannemark M, Orho M \& Groop L (1998) No relationship between identified variants in the uncoupling protein 2 gene and energy expenditure. European Journal of Endocrinology 139, 217-223.

Lammert O \& Hansen ES (1982) Effects of excessive caloric intake and caloric restriction on body weight and energy expenditure at rest and light exercise. Acta Physiologica Scandinavica 114, 135-141.

Lanouette CM, Giacobino JP, Perusse L, Lacaille M, Yvon C, Chagnon M, Kuhne F, Bouchard C, Muzzin P \& Chagnon YC (2001) Association between uncoupling protein 3 gene and obesity-related phenotypes in the Quebec Family Study. Molecular Medicine 7, 433-441.

Lebon V, Dufour S, Petersen KF, Ren J, Jucker BM, Slezak LA, Cline GW, Rothman DL \& Shulman GI (2001) Effect of triiodothyronine on mitochondrial energy coupling in human skeletal muscle. Journal of Clinical Investigation 108, 733-737.

Lentes K-U, Tu N, Chen H, Winnikes U, Reinert I, Marmann G \& Pirke KM (1999) Genomic organization and mutational analysis of the human UCP2 gene, a prime candidate gene for human obesity. Journal of Receptor and Signal Transduction Research 19, 229-244.

Meijer GA, Westerterp KR, Seyts GH, Janssen GM, Saris WH \& ten Hoor F (1991) Body composition and sleeping metabolic rate in response to a 5-month endurance-training programme in adults. European Journal of Applied Physiology and Occupational Physiology 62, 18-21.

Millet L, Vidal H, Andreelli F, Larrouy D, Riou J-P, Ricquier D, Laville M \& Langin D (1997) Increased uncoupling protein-2 and -3 mRNA expression during fasting in obese and lean humans. Journal of Clinical Investigation 100, 2665-2670.

Mitchell P (1966) Chemiosmotic coupling in oxidative and photosynthetic phosphorylation. Biological Reviews of the Cambridge Philosophical Society 41, 445-502.

Nicholls DG \& Locke RM (1984) Thermogenic mechanisms in brown fat. Physiological Reviews 64, 1-64. 
Pedersen SB, Lund S, Buhl ES \& Richelsen B (2001) Insulin and contraction directly stimulate UCP2 and UCP3 mRNA expression in rat skeletal muscle in vitro. Biochemical and Biophysical Research Communications 283, 19-25.

Pilegaard H, Keller C, Steensberg A, Helge JW, Pedersen BK, Saltin B \& Neufer PD (2002) Influence of pre-exercise muscle glycogen content on exercise-induced transcriptional regulation of metabolic genes. Journal of Physiology 541, 261-271.

Pilegaard H, Ordway GA, Saltin B \& Neufer PD (2000) Transcriptional regulation of gene expression in human skeletal muscle during recovery from exercise. American Journal of Physiology 279, E806-E814.

Poehlman ET, Gardner AW, Arciero PJ, Goran MI \& CallesEscandon J (1994) Effects of endurance training on total fat oxidation in elderly persons. Journal of Applied Physiology 76, 2281-2287.

Poehlman ET, Melby CL, Bradylak SF \& Calles J (1988) Resting metabolic rate and postprandial thermogenesis in highly trained and untrained males. American Journal of Clinical Nutrition 47, 793-798.

Pratley R, Nicklas B, Rubin M, Miller J, Smith A, Smith M, Hurley B \& Goldberg A (1994) Strength training increases resting metabolic rate and norepinephrine levels in healthy 50- to 65-yr-old men. Journal of Applied Physiology 76, 133-137.

Ravussin E, Lillioja S, Anderson TE, Christin L \& Bogardus C (1986) Determinants of 24-hour energy expenditure in man. Methods and results using a respiratory chamber. Journal of Clinical Investigation 78, 1568-1578.

Ravussin E, Lillioja S, Knowler WC, Christen L, Freymond D, Abbott WGH, Boyce V, Howard BV \& Bogardus C (1988) Reduced rate of energy expenditure as a risk factor for bodyweight gain. New England Journal of Medicine 318, 467-472.

Ruderman NB, Saha AK, Vavvas D \& Witters LA (1999) Malonyl$\mathrm{CoA}$, fuel sensing, and insulin resistance. American Journal of Physiology 276, E1-E18.

Russell A, Wadley G, Snow R, Giacobino JP, Muzzin P, Garnham A \& Cameron-Smith D (2002) Slow component of [V]O(2)kinetics: the effect of training status, fibre type, UCP3 mRNA and citrate synthase activity. International Journal of Obesity and Related Metabolic Disorders 26, 157-164.

Russell AP, Wadley G, Hesselink MKC, Schaart G, Lo SK, Léger B, Garnham A, Kornips E, Cameron-Smith D, Giacobino JP, Muzzin P, Snow R \& Schrauwen P (2003) UCP3 protein expression is lower in type I, IIa and IIx muscle fiber types of endurance trained compared to untrained subjects. European Journal of Physiology 445, 563-569.

Schrauwen P \& Hesselink MKC (2002) UCP2 and UCP3 in muscle controlling body metabolism. Journal of Experimental Biology 205, 2275-2285.

Schrauwen P, Hesselink MK, Vaartjes I, Kornips E, Saris WH, Giacobino JP \& Russell A (2002a) Effect of acute exercise on uncoupling protein 3 is a fat metabolism- mediated effect. American Journal of Physiology 282, E11-17.

Schrauwen P, Saris WH \& Hesselink MK (2001) An alternative function for human uncoupling protein 3: protection of mitochondria against accumulation of nonesterified fatty acids inside the mitochondrial matrix. FASEB Journal 15, 2497-2502.

Schrauwen P, Schaart G, Saris WH, Slieker LJ, Glatz JF, Vidal H \& Blaak EE (2000) The effect of weight reduction on skeletal muscle UCP2 and UCP3 mRNA expression and UCP3 protein content in Type II diabetic subjects. Diabetologia 43, $1408-1416$

Schrauwen P, Troost FJ, Xia J, Ravussin E \& Saris WH (1999a) Skeletal muscle UCP2 and UCP3 expression in trained and untrained male subjects. International Journal of Obesity and Related Metabolic Disorders 23, 966-972.
Schrauwen P, Van Aggel-Leijssen DP, Hul G, Wagenmakers AJ, Vidal H, Saris WH \& Van Baak MA $(2002 b)$ The effect of a 3-month low-intensity endurance training program on fat oxidation and acetyl-CoA carboxylase-2 expression. Diabetes 51, 2220-2226.

Schrauwen P \& Westerterp KR (2000) The role of high-fat diets and physical activity in the regulation of body weight. British Journal of Nutrition 84, 417-427.

Schrauwen P, Westerterp-Plantenga MS, Kornips E, Schaart G \& van Marken Lichtenbelt WD (2002c) The effect of mild cold exposure on UCP3 mRNA expression and UCP3 protein content in humans. International Journal of Obesity and Related Metabolic Disorders 26, 450-457.

Schrauwen P, Xia J, Bogardus C, Pratley RE \& Ravussin E (1999b) Skeletal muscle uncoupling protein 3 expression is a determinant of energy expenditure in Pima Indians. Diabetes $\mathbf{4 8}$, 146-149.

Schulz LO, Nyomba BL, Alger S, Anderson TE \& Ravussin E (1991) Effect of endurance training on sedentary energy expenditure measured in a respiratory chamber. American Journal of Physiology 260, E257-E261.

Simonsen L, Stallknecht B \& Bulow J (1993) Contribution of skeletal muscle and adipose tissue to adrenaline- induced thermogenesis in man. International Journal of Obesity and Related Metabolic Disorders 17, Suppl. 3, S47-S51, S68.

Simonyan RA, Jimenez M, Ceddia RB, Giacobino JP, Muzzin P \& Skulachev VP (2001) Cold-induced changes in the energy coupling and the UCP3 level in rodent skeletal muscles. Biochimica et Biophysica Acta 1505, 271-279.

Skulachev VP (1998) Uncoupling: new approaches to an old problem of bioenergetics. Biochimica et Biophysica Acta 1363, 100-124.

Tremblay A, Fontaine E, Poehlman ET, Mitchell D, Perron L \& Bouchard C (1986) The effect of exercise-training on resting metabolic rate in lean and obese moderately obese individuals. International Journal of Obesity and Related Metabolic Disorders 10, 511-517.

Tremblay A, Nadeau A, Fournier G \& Bouchard C (1988) Effect of a three-day interruption of exercise-training on resting metabolic rate and glucose-induced thermogenesis in trained individuals. International Journal of Obesity and Related Metabolic Disorders 12, 163-168.

Tsuboyama-Kasaoka N, Tsunoda N, Maruyama K, Takahashi M, Kim H, Ikemoto S \& Ezaki O (1998) Up-regulation of uncoupling protein 3 (UCP3) mRNA by exercise training and down-regulation of UCP3 by denervation in skeletal muscles. Biochemical and Biophysical Research Communications 247, 498-503.

Ukkola O, Tremblay A, Sun G, Chagnon YC \& Bouchard C (2001) Genetic variation at the uncoupling protein 1, 2 and 3 loci and the response to long-term overfeeding. European Journal of Clinical Nutrition 55, 1008-1015.

Vidal-Puig A, Rosenbaum M, Considine RC, Leibel RL, Dohm GL \& Lowell BB (1999) Effects of obesity and stable weight reduction on UCP2 and UCP3 gene expression in humans. Obesity Research 7, 133-140.

Vidal-Puig A, Solanes G, Grujic D, Flier JS \& Lowell BB (1997) UCP3: An uncoupling protein homologue expressed preferentially and abundantly in skeletal muscle and brown adipose tissue. Biochemical and Biophysical Research Communications 235, 79-82.

Vidal-Puig AJ, Grujic D, Zhang CY, Hagen T, Boss O, Ido Y, Szczepanik A, Wade J, Mootha V, Cortright R, Muoio DM \& Lowell BB (2000) Energy metabolism in uncoupling protein 3 gene knockout mice. Journal of Biological Chemistry 275, $16258-16266$. 
Walder K, Norman RA, Hanson RL, Schrauwen P, Neverova M, Jenkinson CP et al. (1998) Association between uncoupling protein polymorphisms (UCP2-UCP3) and energy metabolism/obesity in Pima indians. Human Molecular Genetics 7 , 1431-1435.

Westerterp KR (1998) Alterations in energy balance with exercise. American Journal of Clinical Nutrition 68, 970S-974S.

Westerterp KR, Meijer GAL, Schoffelen P \& Janssen E (1994) Body mass, body composition and sleeping metabolic rate before, during and after endurance training. European Journal of Applied Physiology and Occupational Physiology 69, 203-208.

Wilmore JH, Stanforth PR, Hudspeth LA, Gagnon J, Daw EW, Leon AS, Rao DC, Skinner JS \& Bouchard C (1998) Alterations in resting metabolic rate as a consequence of $20 \mathrm{wk}$ of endurance training: the HERITAGE Family Study. American Journal of Clinical Nutrition 68, 66-71.

Yanovski JA, Diament AL, Sovik KN, Nguyen TT, Li H, Sebring NG \& Warden CH (2000) Associations between uncoupling protein 2 , body composition, and resting energy expenditure in lean and obese African American, white, and Asian children. American Journal of Clinical Nutrition 71, 1405-1420.

Zhou M, Lin BZ, Coughlin S, Vallega G \& Pilch PF (2000) UCP-3 expression in skeletal muscle: effects of exercise, hypoxia, and AMP-activated protein kinase. American Journal of Physiology 279, E622-E629. 